\title{
TRANSCULTURAL PSYCHIATRY
}

*Ms. Jakkulin Lilly Priya C

\section{INTRODUCTION}

Transcultural psychiatry in the strict literal sense of the term means that the vista of the observer extends beyond the scope of one cultural unit into others.

\section{TRANSCULTURAL PSYCHIATRY:}

"The discipline that deals with the description, definition, assessment and management of all psychiatric conditions as they reflect and are subjected to the influence of cultural factors in a biopsychosocial context while using concepts and instruments from social and biological sciences to advance a full understanding of psychopathology and its treatment"

\section{SCOPE AND CONTENT OF} TRANSCULTURAL PSYCHIATRY

- Exploration of similarities and differences in the manifestations of mental illness in different cultures.

- Identification of cultural factors that predispose to mental illness and mental health.

- Assessment of the effect of identified cultural factors on the frequency, nature and distribution of mental illness.

- Attitude toward the mentally ill in different cultures.

- Study of the forms of care and treatment practised or preferred in different cultural settings.

- Culture and clinical practice, including the clinician-patient relationship.

- Design and evaluation of mental health services in multicultural societies.
- Human rights concerns

CULTURE INFLUENCES PERSONALITY DEVELOPMENT AND GENESIS OF MENTAL ILLNESS:

- Too much of individual freedom

- Overvaluation of one sex. E.g. Hindu society

- Child rearing practices

- Societies where inbreeding is encouraged

- Low socio economic status

- Birth order

CULTURAL VARIANTS IN SYMPTOMATOLOGY

- Schizophrenia patients from African bush areas are different from those from the urban areas.

- Depressive illness in some countries has major somatic contents.

- Hysteria, both conversion and dissociation are more common in developing countries.

- Obsessive compulsive neurosis is rare in some eastern countries

\section{CULTURAL- BOUND SYNDROMES}

\section{Amoke}

This is a sudden unprovoked outburst of wild rage that causes the affected person to run about, usually armed with knife, and to attack or maim or kill indiscriminately all men and animals in his way before he is overpowered, or kills himself.

\footnotetext{
*Lecturer, College of Nursing, PIMS, Puducherry.
} 


\section{Latah}

This is seen exclusively among Malays in Malaya. There are two clinical forms:

- Startle reaction, a sudden stimulus provokes the suspension of all normal activity and triggers a set of unusual inappropriate motor and verbal manifestations over which the affected person has no voluntary control.

- Echo reaction: a sudden stimulus compels the affected person to imitate any action or words to which he is exposed.

\section{Koro}

This is an acute anxiety reaction characterized by the patients desperate fear that his penis is shrinking and may disappear into his abdomen in which case he will die.

\section{Dhat}

This is acute anxiety reaction, which has some resemblance to koro and which is reported in some parts of India. This is usually associated with frequent masturbation or coitus.

\section{Piblokto}

This is also called 'Arctic hysteria' and reported among Eskimos more common among women.

- The victims screams, shouts, tears off cloths, imitates birds or animals and runs about.

- This last about 1 or 2 hours, after which the victim settles down, become normal and has amnesia about the episode.

\section{Possession States}

In Chinese trance states, the victims identify themselves with the dead.

- It is commonly reported in Indian villages.

- The victims are usually middle aged women who behave as though they are possessed by gods, evil spirits or spirits of close relatives and friends who have met with unnatural death.

\section{Whindigo}

- This is a rare condition reported among north American Indians. In times of starvation some get the extreme fear that they may be transformed into supernatural monster whindigo that eats human flesh and notorious in mythology.

- The victim experiences imperious urge to satisfy a cannibalistic appetite.

\section{Voodoo}

- This is a religious cult Africans and west Indians.

- At a typical voodoo ceremony, which consist of dancing to the wild rhythm of drums, several people, usually women, gets attacks of trances, convulsions and excitement.

- This is a dissociative reaction, very similar to possession states and provides emotional catharsis.

\section{Cargo Cult}

- The 'soul loss' is treated by black magic. This is reported in New Guinea where a leader emerges and announces a great future events.

- Preparation are made to deal with the expected changes.

- New forms of morality are adopted.

- Preparations are made to receive the ancestral spirits to bring in the highly valued cargo.

\section{Susto}

- This is again an acute anxiety reaction in Peru. 
- It is the belief that the soul has left the body and is kidnapped by earth, and is similar to Koro and Dhat.

\section{CULTURE AND TREATMENT PROGRAMMES:}

\section{Morita Therapy}

- It directed behavior change is the objective of treatment.

\section{Phases Of Treatment:}

1. Absolute rest

2. Period of light work

3. Period of moderate work

4. Period of preparation to go back and lead a normal life.

\section{Family Therapy}

- A family therapy practiced in Vellore (India).

- Family involvement in the treatment in other places in India such as Amritsar and Bangalore.

- Each patient will be given a small flat, so that the family can have their privacy.

\section{INCREASING TRANSCULTURAL MENTAL HEALTH RESEARCH}

\section{Research and the policy cycle}

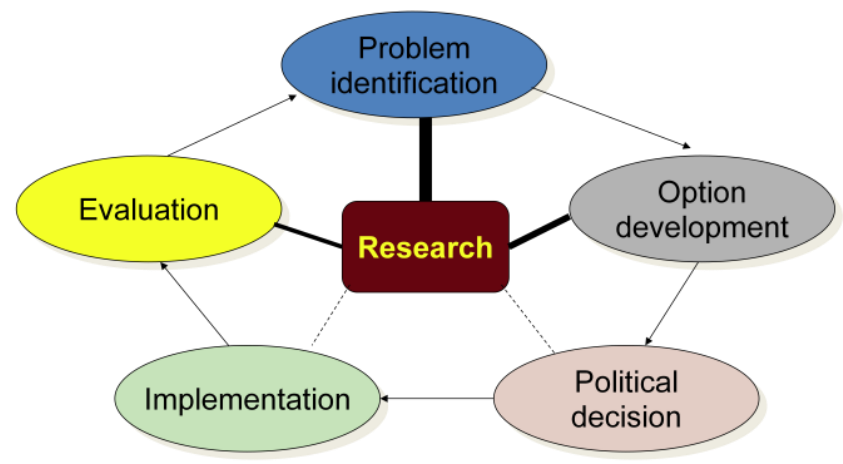

More systematic and intelligent use of existing data coliections

e.g. service use and outcomes data
Ensure that essential data fields (e.g. country birth, COB of parents in CAMHS, English fluency) are included in routine data collections

- Promote high quality service evaluation as an essential component of service delivery

- Confront ethics of exclusion

- Epidemiological and treatment efficacy studies should be based on truly representative samples of the population (NH\&MRC, ARC, etc.)

- Development of transcultural mental health research instruments and methods

- Teaching programs in transcultural mental health research methods and ethics

Attract an increased number of Master and $\mathrm{PhD}$ students who are doing transcultural mental health research projects

- Transcultural mental health research capacity

- Competitive research funding for the field

- Body of useful information

\section{REFERENCE}

1. Sadock, Benjamin J.; Sadock, Virginia A.; Ruiz, Pedro Kaplan \& Sadock's Comprehensive Textbook of Psychiatry, 9th Edition.

2. NEKI, J. S. (1976) An examination of the cultural relativism of dependence as a dynamic of social and therapeuticrelationships. II. Therapeutic. British Journal of Medical Psychology, 49: 11-22.

3. Burr J A \& Chapman T (1998) Some reflections on cultural and social considerations in mental health nursing. Journal of Psychiatric and Mental Health Nursing 5:431-437 